\title{
Macronutrient intakes and cardio metabolic risk factors in high BMI
} African American children

\author{
Sushma Sharma*1,2, Lindsay S Roberts ${ }^{1,2}$, Mark L Hudes ${ }^{1,2}$, Robert H Lustig ${ }^{1,3}$ \\ and Sharon E Fleming ${ }^{1,2}$
}

\begin{abstract}
Address: ${ }^{T}$ The Dr Robert C and Veronica Atkins Center for Weight and Health, University of California, Berkeley, CA 94720-3100, USA, ${ }^{2}$ Department of Nutritional Sciences and Toxicology, University of California, Berkeley, CA 94720-3104, USA and ${ }^{3}$ Division of Pediatric Endocrinology, University of California, San Francisco, CA 94143, USA
\end{abstract}

Email: Sushma Sharma* - sushma@berkeley.edu; Lindsay S Roberts - lindsayroberts@berkeley.edu; Mark L Hudes - mlhudes@hotmail.com; Robert H Lustig - RLustig@peds.ucsf.edu; Sharon E Fleming - sfleming@berkeley.edu

* Corresponding author

Published: 13 October 2009

Nutrition \& Metabolism 2009, 6:4| doi:|0.1|86/|743-7075-6-4|
Received: 6 August 2009

Accepted: 13 October 2009

This article is available from: http://www.nutritionandmetabolism.com/content/6/l/4I

(C) 2009 Sharma et al; licensee BioMed Central Ltd.

This is an Open Access article distributed under the terms of the Creative Commons Attribution License (http://creativecommons.org/licenses/by/2.0), which permits unrestricted use, distribution, and reproduction in any medium, provided the original work is properly cited.

\begin{abstract}
Background: The aim of this study was to evaluate the relationship between intakes of energyproviding macronutrients, and markers of cardio metabolic risk factors in high BMI African American (AA) children.

Methods: A cross sectional analysis of a sample of 9-1 I year old children $(n=80)$ with BMl greater then the $85^{\text {th }}$ percentile. Fasting hematological and biochemical measurements, and blood pressure were measured as selected markers of cardio metabolic risk factors and their relationships to dietary intakes determined.

Results: After adjusting for gender, pubertal stage and waist circumference (WC), multivariate regression analysis showed that higher total energy intakes (when unadjusted for source of energy) were associated with higher plasma concentrations of intermediate density lipoprotein cholesterol (IDL-C) and very low density lipoprotein cholesterol (VLDL-C). Higher intakes of carbohydrate energy (fat and protein held constant) were associated with higher IDL-C, VLDL-C, triglycerides (TG) and homeostasis model assessment of insulin resistance (HOMA-IR). Higher intakes of fat (carbohydrate and protein held constant), however, were associated with lower IDL-C; and higher protein intakes (fat and carbohydrate held constant) were associated with lower HOMA-IR.

Conclusion: The specific macronutrients that contribute energy are significantly associated with a wide range of cardio metabolic risk factors in high BMI AA children. Increases in carbohydrate energy were associated with undesirable effects including increases in several classes of plasma lipids and HOMA-IR. Increases in protein energy were associated with the desirable effect of reduced HOMA-IR, and fat energy intakes were associated with the desirable effect of reduced IDL-C. This analysis suggests that the effect of increased energy on risk of developing cardio metabolic risk factors is influenced by the source of that energy.
\end{abstract}




\section{Background}

In the past three decades, the prevalence of overweight and obesity among youth in the USA has doubled and tripled, respectively [1]. Obesity during childhood and adolescence is associated with a number of cardiovascular disease risk factors including type 2 diabetes mellitus, hypertension, and dyslipidemia. Many studies including the Muscatine Study [2,3] and the Bogalusa Heart Study [4] have convincingly shown that overweight and obesity during adolescence is a determinant of a number of CVD risk factors in adulthood. A clinical report published by the American Academy of Pediatrics also suggests that because of their high risk of developing CVD, overweight children are in need of cholesterol screening regardless of family history or other risk factors [5].

Ethnicity also plays an important role in the development of the cardio metabolic syndrome. The African American (AA) population has been shown to be at higher risk for the metabolic syndrome than whites [6] and, as the prevalence of obesity and the metabolic syndrome in AA children is on the rise [7], risk factors management should begin at an early age.

Recently, there has been growing evidence that childhood diet may have important implications for the development of obesity and chronic disease in later life. Health professionals have suggested that the dietary habits of children and adolescents need serious attention. It has been established that management of energy intakes from different macronutrients plays a more important role in the development of obesity and metabolic complications than does total energy alone. Studies examining the early natural history of heart disease have demonstrated the relationship between early dietary habits, such as high intake of energy from fat, and the subsequent development of CVD $[8,9]$. Replacement of dietary saturated fat with carbohydrate has been shown to increase triglycerides (TG) in adults [10]. Similarly, studies have found an association between protein intake in childhood and changes in body fatness later in life, generating a hypothesis that high levels of protein consumption in early childhood may lead to the later development of obesity $[11,12]$. Thus, metabolic diseases in later life may be attenuated by careful selection of which macronutrients are consumed during childhood, and the amount of each.

Efforts have been made to investigate the influence of dietary components on selected cardio metabolic risk factors in adults [13] and in children of various ethnicities [1416]. Most studies, however, have studied replacement effects where, by definition, intakes of at least 2 energyproviding dietary components are altered. Such an approach cannot determine which component of these components is responsible for observed effects. Thus, the main objective of this study was to determine the relationship between each dietary macronutrient independently of the other two, and cardio metabolic risk factors in high BMI AA children.

\section{Methods \\ Subjects}

Subjects included in this analysis represented a cross-sectional convenience sample of children enrolled in Taking Action Together, an ongoing 2-year YMCA-based intervention trial to reduce the risk of diabetes in high BMI 9-11 year old African American children from inner-city urban neighborhoods. All participants were 9-11 years old, with high BMI's above the 85th percentile, fasting glucose $<120$ $\mathrm{mg} / \mathrm{dl}$, free from any known metabolic diseases, and were not taking medications known to affect the study outcomes. Study participants were recruited by distributing pamphlets at local recreational sites and schools in innercity Oakland, CA. Parental informed consent were obtained for all subjects, and all protocols were approved by institutional review boards at the University of California, Berkeley and San Francisco. A complete set of data were available for a total 84 children (38 boys and 46 girls).

\section{Anthropometric Measurements}

Body weight and height were measured to the nearest 0.1 $\mathrm{kg}$ and $0.1 \mathrm{~cm}$ using a digital electronic scale (BWB 800, Tanita, Japan), and a portable stadiometer, respectively. Body mass index (BMI), BMI percentiles and BMI z-scores were generated using an age and gender specific CDC calculator http://www.cdc.gov/nccdphp/dnpa/growth charts/resources/sas.htm. For simplicity, the term "high BMI" has been used in this paper to collectively refer to children defined by an expert committees, and based on CDC growth charts [17-19], as being either "at risk of overweight". (BMI's between 85th and 95th percentil) or "Overweight/Obese" (BMI's at or above 95th percentile).

Using a plastic non-elastic measuring tape, waist circumference was measured just above the iliac crest with child the standing position. Measurements were taken twice and if agreement between repeats was greater than $0.4 \mathrm{~cm}$, a third measurement was taken and the mean calculated using the closest two values [20]. Total body resistance was measured using bioelectrical impedance analysis (Model BIA-101Q; RJL systems, Detroit, MI) according to manufacturer's instructions [20], and percent body fat was computed using Horlick's equation [21]. This method and equation have been validated in AA children previously.

\section{Blood Pressure (BP) Measurements}

Blood pressure measurements were taken between 0800 and $1200 \mathrm{hr}$. Children were asked to rest for a duration of 
15-20 minutes in a sitting position after which they were measured with a manual sphygmomanometer by highly trained individuals. Measurements were repeated until two consecutive systolic and diastolic measurements agreed within 4 and $2 \mathrm{~mm} \mathrm{Hg}$, respectively. This series of measurements was repeated twice in children, with repeats spaced at least $2 \mathrm{hr}$ apart, and the second series of measurements used for analyses. Data were analyzed using both systolic and diastolic pressures, and after conversion to blood pressure percentiles (matched for age, height and gender) using regression equations developed and reported elsewhere [22].

\section{Biochemical Measurements}

Subjects reported to Children's Hospital and Research Center, Oakland CA after a $12 \mathrm{hr}$ overnight fasting when their blood was drawn. Plasma lipids were measured by a comprehensive lipoprotein analysis performed by a commercial lab (LabCorp). Using the vertical auto profile (VAP)-cholesterol method a modified density gradient centrifugation technique, concentrations of the cholesterol content of all lipoprotein subclasses (total cholesterol, HDL-cholesterol, LDL-cholesterol, IDL-cholesterol, VLDL-cholesterol) and triglycerides were determined on a single sample [23].

Fasting plasma glucose was determined using a hexokinase- peroxidase method (glucose HK-60 assay; Diagnostic Chemicals, Oxford, CT). Reference standards of normal and elevated glucose concentration (DCTrol;Diagnostic Chemicals, Oxford, CT) were analysed with each assay for quality-control purposes.

Fasting serum insulin concentrations were determined using enzyme-immunoassay (Linco, St. Charles, MO). The insulin assay has $<1 \%$ cross-reactivity with proinsulin. The intra-assay variation was $4.5 \%$ and inter-assay variation was $10 \%$

Fasting glucose and insulin values were used to calculate insulin resistance [24] using the homeostasis model assessment of insulin resistance (HOMA-IR), defined as fasting glucose $(\mathrm{mmol} / \mathrm{l}) \times$ insulin $(\mu \mathrm{U} / \mathrm{ml}) / 22.5$.

Serum non esterified free fatty acids (NEFA) were measured using an in vitro enzymatic colorimetric assay (NEFA, Wako Diagnostics, USA) and used to calculate Fatty acid insulin sensitivity (ISI-FFA) by the formula: $\{2 /$ (insulin $\times$ NEFA $)+1\}$ [25]

Pubertal development was assessed by measurements of serum luteinizing hormones (LH) in boys and estradiol and LH in girls. Children were classified into stages 1 through 5 using literature-derived values [26-31]. The hormone concentrations included in the 5-pubertal stages were as follows: $0-11.6,11.61-26.2 ; 26.21-50.7 ; 50.71$ 64.9 and $>64.91 \mathrm{pg} / \mathrm{mL}$ for $\mathrm{E}_{2}$ in girls; 0-0.4, 0.41-3.4; 3.41-4.1; 4.11-5.9 and $>5.91 \mathrm{IU} / \mathrm{L}$ for $\mathrm{LH}$ in girls; and 0 $0.7,0.71-1.6 ; 1.61-2.6 ; 2.61-3.1$ and $>3.11 \mathrm{IU} / \mathrm{L}$ for $\mathrm{LH}$ in boys. When $\mathrm{E}_{2}$ and LH hormone concentrations in girls suggested different pubertal stages, the higher stage was assigned to that girl [31].

\section{Energy intake}

Three-day food diaries were used to assess intakes of nutrients as they have been shown to be a more accurate tool for diet assessment than 24-h diet recall or food frequency questionnaire methods [32]. Before completing a 3-day food diary ( 2 weekdays and 1 weekend day), participating children and a parent/guardian were trained to record portion sizes, brand names, place consumed, and time of day food was consumed. Trained staff reviewed the questionnaires with the child, expanding on descriptions of foods and portion sizes when needed.

Macronutrient intakes were determined using the USDA nutrient database [33]. To do this, the foods listed on the 3-day food diaries were labeled according to the 8-digit food codes, portion sizes or weights were entered into this software, and computer programs were used to calculate the 3-day average intakes of energy and specific macronutrients. Analyses were carried out on the data set as a whole and, following the protocol for the National Health and Nutrition Examination Survey (NHANES), no quantification or exclusion for underreporting or over reporting was made. Average daily intakes of energy (kcal/day) and of the macronutrients, carbohydrates, fat and protein (g/day) were used for analyses.

\section{Statistical Analyses}

Statistical procedures were performed using SPSS for Windows version 16.0 (SPSS Inc, Chicago, IL). Statistical significance was defined to be $\mathrm{p} \leq 0.05$. Results with $0.05<\mathrm{p}$ $<0.10$ were also noted to show close associations. Differences in the anthropometric and lipoprotein profiles in boys versus girls were performed using independent $t$ tests. Dixon's test for outliers was used to identify unusual values. When identified, all data for that participant were excluded from further analyses. Using Dixon's test, data for 4 children were excluded. Data for the variables of interest were not significantly skewed. Correlations were used to evaluate bivariate associations among dependent and independent variables including intakes of total energy, fat, carbohydrate and protein, and biochemical and blood pressure variables of interest. As associations between these variables were similar for Pearsons and Spearmans correlations, values are reported only for Pearsons correlations, and parametric tests were used in subsequent analyses. Multiple linear regression analyses were used to assess the relationship of total energy intake 
(unadjusted for source of energy), or, individually, of fat, carbohydrate and protein to TC, VLDL-C, IDL-C, LDL-C, HDL-C, TG, HOMA-IR, NEFA, ISI-FFA, sBPz and $\mathrm{dBPz}$ after adjusting for gender, pubertal stage and waist circumference of the participating child. Child age was not included as a covariate since it was not significantly correlated with dependent or independent variables.

As might be expected BMIz and WC were highly correlated $(\mathrm{r}=0.87, \mathrm{p}<0.001)$. In addition, WC and BMI were both associated with markers of cardio metabolic risk factors including TG (BMIz r = 0.34; WC $\mathrm{r}=0.30)$, HDL-C (BMIz $\mathrm{r}=-0.40$; WC $\mathrm{r}=-0.46)$, HOMA-IR (BMIz $\mathrm{r}=0.60$; WC $\mathrm{r}=$ $0.57)$, ISI-FFA (BMIz r = -0.57; WC $\mathrm{r}=-0.55), \mathrm{sBPz}(\mathrm{BMIz}$ $r=0.25 ;$ WC $r=0.28) \mathrm{dBPz}(\mathrm{BMIz} r=0.23 ; \mathrm{WC} \mathrm{r}=0.87)$. Because WC is included in the National Cholesterol Education Program (NCEP) ATP III recommendations [34], WC was chosen for results presentation and discussion.

\section{Results}

Girls enrolled in this study were sexually more mature than boys and had significantly higher body weight, body fat \%, BMI-z scores, WC, TG, insulin, HOMA-IR and NEFA than boys (Table 1). Boys had significantly higher ISI-FFA than girls. Intakes of energy and macronutrients did not differ significantly by gender.

Pearson correlations were used to evaluate the inter-relationship between selected cardio metabolic risk factors. Although the lipoprotein cholesterol subclasses tended to be inter-related, HDL-C was not significantly associated with LDL-C and IDL-C; and TG was not significantly associated with TC. LDL-C was significantly associated with IDL-C $(\mathrm{r}=0.61, \mathrm{p}<0.001)$ and VLDL-C $(\mathrm{r}=0.32, \mathrm{p}<$ $0.01)$. TC was significantly associated with all lipoprotein cholesterol subclasses i.e. HDL-C $(\mathrm{r}=0.41$, $\mathrm{p}<0.001)$, LDL-C ( $\mathrm{r}=0.94, \mathrm{p}<0.001)$, IDL-C $(\mathrm{r}=0.60, \mathrm{p}<0.001)$ and VLDL-C $(\mathrm{r}=0.29, \mathrm{p}<0.01)$. As expected, TG was highly associated with VLDL-C $(\mathrm{r}=0.88, \mathrm{p}<0.001)$ and IDL-C $(\mathrm{r}=0.64, \mathrm{p}<0.001)$. HOMA-IR and ISI-FFA were highly and negatively associated $(\mathrm{r}=-072, \mathrm{p}<0.001)$. HOMA-IR was also associated with HDL-C $(\mathrm{r}=-0.33, \mathrm{p}<$ $0.001)$, VLDL-C $(\mathrm{r}=0.29, \mathrm{p}<0.01)$ and TG levels $(\mathrm{r}=$ $0.48, \mathrm{p}<0.001)$ whereas ISI-FFA was significantly associated with HDL-C $(\mathrm{r}=0.43, \mathrm{p}<0.001)$ and TG $(\mathrm{r}=-0.44$, $\mathrm{p}<0.001)$. sBPz was associated with VLDL-C $(\mathrm{r}=0.23, \mathrm{p}$ $<0.05)$ and $\mathrm{dBPz}(\mathrm{r}=0.37, \mathrm{p}<0.001)$. dBPz was significantly associated with LDL-C $(r=0.24, \mathrm{p}<0.05)$, IDL-C ( $\mathrm{r}$ $=0.31, \mathrm{p}<0.05)$, VLDL-C $(\mathrm{r}=0.39, \mathrm{p}<0.01), \mathrm{TG}(\mathrm{r}=$ $0.31, \mathrm{p}<0.01)$.

Also, using bivariate analysis, total energy intake was significantly correlated with IDL-C $(\mathrm{r}=0.22, \mathrm{p}<0.05)$, and VLDL-C $(\mathrm{r}=0.22, \mathrm{p}<0.05)$ and $\mathrm{sBP}(\mathrm{r}=0.23, \mathrm{p}<0.05)$. Carbohydrate intake was positively associated with TG ( $\mathrm{r}$
$=0.27, \mathrm{p}<0.05)$, VLDL-C $(\mathrm{r}=0.30, \mathrm{p}<0.01)$ and IDL- $\mathrm{C}$ $(\mathrm{r}=0.34, \mathrm{p}<0.01)$. Protein and Fat intake were associated by $\operatorname{sBP}(\mathrm{r}=0.22, \mathrm{p}<0.05$ for both $)$.

Using regression analysis, total energy intakes, without adjustment for the source of the energy, were significantly and positively associated with IDL-C $(\mathrm{p}<0.05)$ and VLDL-C ( $\mathrm{p}<0.05)$ after accounting for child's gender, pubertal stage and WC (Model 1, Table 2).

In a second regression model (Model 2, Table 2), carbohydrate intakes, with fat and protein intakes held constant, were significantly and positively associated with IDL-C ( $\mathrm{p}<0.01)$, VLDL-C ( $\mathrm{p}<0.01)$, TG $(\mathrm{p}<0.01)$ and HOMA-IR ( $\mathrm{p}<0.05)$; and closely but negatively associated with ISI-FFA $(0.05<\mathrm{p}<0.10)$. Fat intakes, with carbohydrate and protein intakes held constant, were found to be significantly and negatively associated with IDL-C ( $\mathrm{p}$ $<0.05)$. Protein intakes, with fat and carbohydrate held constant, was negatively associated with HOMA-IR ( $\mathrm{p}<$ $0.05)$.

Figure 1 summarizes the association between macronutrients and selected cardio metabolic risk factors. Increases in energy from carbohydrate were associated with the undesirable effect of increased HOMA-IR, TG, VLDL-C and IDL-C. Increases in protein energy were associated with the desirable effect of reduced HOMA-IR; and increase in fat energy was associated with the desirable effect of reduced IDL-C. The significance of results from multivariate regression analyses were unchanged regardless of whether BMIz or WC was included in the models (data with BMIz not presented). Additionally, the significance of results were unchanged regardless of whether child gender or pubertal stages were included in the models (data without gender and pubertal stage not presented).

\section{Discussion}

Our main outcomes highlight the association between intakes of energy from each of the three classes of macronutrient and important cardio metabolic risk factors in high BMI, AA children. Although the risk for type2 diabetes is known to be higher for AA than white children [35], few data on the influence of specific macronutrients on risks for this condition in AA children are available. We (20) and others [36,37] have previously reported that obesity in AA children predisposes them to insulin resistance early in life. In the present analyses, WC and BMI zscores both showed positive associations with $T G$, HOMA-IR, sBPz, dBPz and negative association with HDL-C and ISI-FFA. This is also consistent with previous studies reporting that overweight status and obesity are important risk factors CVD $[3,4,6,7]$. WC, used in these analyses, is a better assessment of visceral adiposity than 
Table I: Characteristics of participating African-American Boys and Girls

\begin{tabular}{|c|c|c|c|}
\hline & Boys $(n=36)$ & Girls $(n=44)$ & $p$-value ${ }^{a}$ \\
\hline & \multicolumn{2}{|c|}{ Mean (SD) } & \\
\hline \multicolumn{4}{|l|}{ Anthropometrics } \\
\hline Age (years) & $10.72(1.06)$ & $10.53(1.12)$ & ns \\
\hline Pubertal stage (I-5) & $2.24(1.52)$ & $3.42(1.21)$ & 0.001 \\
\hline Height (m) & $1.48(0.09)$ & $1.50(0.08)$ & ns \\
\hline Weight (kg) & $57.62(18.11)$ & $66.34(14.23)$ & 0.010 \\
\hline Body fat (\%) & $32.34(9.02)$ & $40.63(7.70)$ & $<0.001$ \\
\hline BMI-z score & $\mathrm{I} .82(0.5 \mathrm{I})$ & $2.13(0.46)$ & 0.005 \\
\hline WC (cm) & $83.62(15.51)$ & $90.73(12.63)$ & 0.020 \\
\hline \multicolumn{4}{|c|}{ Biochemical parameters } \\
\hline $\mathrm{TC}(\mathrm{mmol} / \mathrm{l})$ & $4.23(0.14)$ & $4.43(0.15)$ & ns \\
\hline $\mathrm{HDL}-\mathrm{C}(\mathrm{mmol} / \mathrm{l})$ & $1.48(0.03)$ & $1.38(0.12)$ & ns \\
\hline LDL-C (mmol/l') & $2.34(0.21)$ & $2.62(0.33)$ & ns \\
\hline IDL-C (mmol/l) & $0.21(0.08)$ & $0.24(0.21)$ & ns \\
\hline VLDL-C (mmol/l) & $0.39(0.03)$ & $0.4 I(0.0 I)$ & ns \\
\hline TG (mmol/l) & $0.68(0.16)$ & $0.83(0.23)$ & 0.020 \\
\hline Insulin $(\mu \mathrm{lU} / \mathrm{ml})$ & $8.01(4.91)$ & $13.06(5.08)$ & 0.001 \\
\hline HOMA-IR & $1.71(1.12)$ & $3.20(2.79)$ & 0.001 \\
\hline NFFA (mEq/L) & $25.72(5.22)$ & $28.93(4.54)$ & 0.005 \\
\hline ISI-FFA & $0.4 \mathrm{I}(0.2 \mathrm{I})$ & $0.21(0.14)$ & $<0.001$ \\
\hline \multicolumn{4}{|l|}{ Blood Pressure } \\
\hline $\mathrm{sBP}(\mathrm{mm} \mathrm{Hg})$ & $105.94(8.90)$ & $104.32(7.22)$ & ns \\
\hline $\mathrm{dBP}(\mathrm{mm} \mathrm{Hg})$ & $61.73(8.67)$ & $62.25(7.07)$ & ns \\
\hline sBP-z score & $0.03(0.74)$ & $-0.13(0.75)$ & ns \\
\hline dBP-z score & $-0.06(0.7 I)$ & $-0.03(0.67)$ & ns \\
\hline \multicolumn{4}{|l|}{ Dietary variables } \\
\hline Total energy (kcal/day) & $1805.03(534.42)$ & I743.95 (593.9|) & ns \\
\hline Carbohydrate (g/day) & $210.41(64.62)$ & $222.74(77.50)$ & ns \\
\hline Fat (g/day) & $77.94(27.72)$ & $69.24(29.75)$ & ns \\
\hline Protein (g/day) & $68.84(22.01)$ & $62.85(21.92)$ & ns \\
\hline
\end{tabular}

ap values calculated from two-sample t-tests

ns, non significant; WC, waist circumference; TC, total cholesterol; HDL-C, HDL cholesterol; LDL-C, LDL cholesterol; IDL-C, IDL cholesterol; VLDL-C, VLDL cholesterol; TG, triglycerides; HOMA-IR, homeostasis model assessment of insulin resistance; NEFA, Non-esterified fatty acids; ISIFFA, fatty acid insulin sensitivity; sBP, systolic blood pressure; $\mathrm{dBP}$, diastolic blood pressure.

BMI or skin-fold measurements [38], and is one of the criteria used to study cardio metabolic risk [39].

In Model 1 (Table 2), increases in energy intakes (regardless of source) were associated with increased VLDL-C and IDL-C but not significantly with any of the other cardio metabolic risk factors evaluated in this study. A larger sample size would be needed to determine whether the close association $(0.05<\mathrm{p}<0.10)$ with $\mathrm{sPBz}$ would then be significant or not. Evaluating the influence of the type of macronutrient contributing in the increased energy, however, provides additional insight. To do this, all 3 macronutrients were entered simultaneously into a second regression model, allowing the influence of one to be evaluated with levels of the other two held constant. This approach differs from approaches often used by others to evaluate the relationship of macronutrients to cardio metabolic risk factors $[10,15]$.
In Model 2, with fat and protein intakes fixed, increased intakes of energy from carbohydrate were associated with undesirable increases in circulating levels of IDL-C, VLDLC, TG and hepatic insulin resistance (HOMA-IR). Carbohydrate also showed a close negative association $(0.05<\mathrm{p}$ $<0.10$ ) with adipose tissue insulin sensitivity (ISI-FFA). It is likely that increased carbohydrate energy intake affects the adipocyte by suppressing the efficiency with which insulin exerts its inhibitory effect on TG hydrolysis, allowing NEFA release from endogenous TG. Accumulation of NEFA in plasma indicates energy-replete peripheral cells, promoting hepatic incorporation of these fatty acids, along with newly synthesized NEFA, into TG which will be packaged into VLDL and metabolized to IDL. Unfavorable relationships between higher carbohydrate and TG $[10,13,40]$ and the prevalence of atherogenic dyslipidemia $[41,42]$ have been observed by others also. Independently of TG, however, high NEFA levels are known to be strongly associated with multiple indices of metabolic dysfunction including metabolic syndrome and cardio- 
Table 2: Standardized regression coefficients from multiple linear regression models evaluating the relationship between total energy and individual macronutrients intakes, and cardio metabolic risk factors $(n=80)$.

\begin{tabular}{|c|c|c|c|c|}
\hline \multirow[t]{3}{*}{ Dependent variables } & \multicolumn{4}{|c|}{ Independent Variables } \\
\hline & \multirow{2}{*}{$\begin{array}{l}\text { Model Ia } \\
\text { Total Energy }\end{array}$} & \multicolumn{3}{|c|}{ Model 2a } \\
\hline & & Carbohydrate & Fat & Protein \\
\hline TC & 0.162 & 0.053 & -0.129 & 0.288 \\
\hline HDL-C & -0.030 & -0.035 & -0.035 & 0.044 \\
\hline LDL-C & 0.171 & 0.031 & -0.107 & 0.300 \\
\hline IDL-C & $0.243 *$ & $0.457 * *$ & $-0.437 *$ & 0.276 \\
\hline VLDL-C & $0.232 *$ & $0.396 * *$ & -0.206 & 0.068 \\
\hline TG & 0.171 & $0.422 * *$ & -0.163 & -0.085 \\
\hline HOMA-IR & -0.024 & $0.302 *$ & -0.025 & $-0.34 I *$ \\
\hline NEFA & -0.141 & 0.077 & -0.127 & -0.116 \\
\hline ISI-FFA & 0.052 & $-0.206 \#$ & 0.138 & 0.139 \\
\hline sBPz & $0.208 \#$ & 0.119 & 0.108 & 0.001 \\
\hline $\mathrm{dBPz}$ & 0.136 & 0.218 & -0.085 & 0.020 \\
\hline
\end{tabular}

Significance: \# for $0.05<p<0.10$, * for $p<0.05$, ** for $p<0.01$, *** for $p \leq 0.001$.

a Multiple linear regression models for total energy (Model I-- no adjustment for source of energy) and macronutrients (Model 2-- influence of one change in one macronutrient assessed when intakes of the other 2 macronutrients are held constant) after adjusting for gender, pubertal stage and WC (independent variables).

TC, total cholesterol; HDL-C, HDL cholesterol; LDL-C, LDL cholesterol; IDL-C, IDL cholesterol; VLDL-C, VLDL cholesterol; TG, triglycerides; HOMA-IR, homeostasis model assessment of insulin resistance; NEFA, Non-esterified fatty acids; ISI-FFA, fatty acid insulin sensitivity; sBP, systolic blood pressure; dBP, diastolic blood pressure.

vascular mortality [43]. In our study, although carbohydrate intakes were not associated with increased concentrations of NEFA, the close and negative association between carbohydrate intake and ISI-FFA $(0.05<\mathrm{p}<$ 0.10 ) and the significant association with HOMA-IR ( $\mathrm{p}<$ 0.05 ) suggests that carbohydrate may negatively affect insulin sensitivity in both hepatocytes and adipocytes.

With carbohydrate and fat intakes held constant, increased intakes of energy from protein were not significantly associated with levels of circulating lipids or lipoproteins, although there was a significant protective effect of protein on hepatic insulin sensitivity (HOMA-IR). Others have reported that increasing percent energy from protein (without adjusting for energy from carbohydrate or fat) is associated with significantly lower fasting glucose concentrations in AA children [15]. It is possible that the effects ascribed to protein by others are actually due to reciprocal decreases in one or both of the other macronutrients.

In Model 2 (Table 2), with carbohydrate and protein intakes held constant, increased intakes of energy from fat was associated with significantly lower IDL-C. A significant negative relationship between TG concentrations and fat intake has been reported previously in AA children [15] but the effect of fat in that study could not be distinguished from corresponding changes in carbohydrate and/or protein. In our study, after controlling both carbohydrate and protein, fat intake was not significantly associated with TG concentrations in AA children.
Although high BP is associated with obesity in AA children [44], a lack of relationships between BP and dietary energy has been reported previously $[15,16]$. In our study, neither total energy intake, nor intakes of energy from any of the three macronutrients was significantly associated with either systolic or diastolic blood pressures in these children.

Limitations of this study include restriction to lowincome, inner-city, African American children and exclusion of children with BMI's less than the $85^{\text {th }}$ percentile when matched for age and gender. These limitations preclude comparisons among children of different races, ages and socioeconomic backgrounds, and comparisons with lower BMI children. The limitations inherent in collecting dietary data, regardless of population, are also recognized. This is a cross-sectional analysis of data, precluding a cause and effect relationship. Future longitudinal studies with measurements at several time-points would be needed to evaluate a causal relationship.

\section{Conclusion}

Based on the data in this study, we conclude that increases in energy from carbohydrate should be discouraged, whereas increases from protein or fat would be of less concern. Associations in this study, between diet components and cardio metabolic risk factors point to the need to target these children for nutrition intervention.

\section{Abbreviations}

AA: African American; BMI: Body mass index; CVD: Cardio vascular disease; dBPz: diastolic blood pressure $\mathrm{z}$ - 


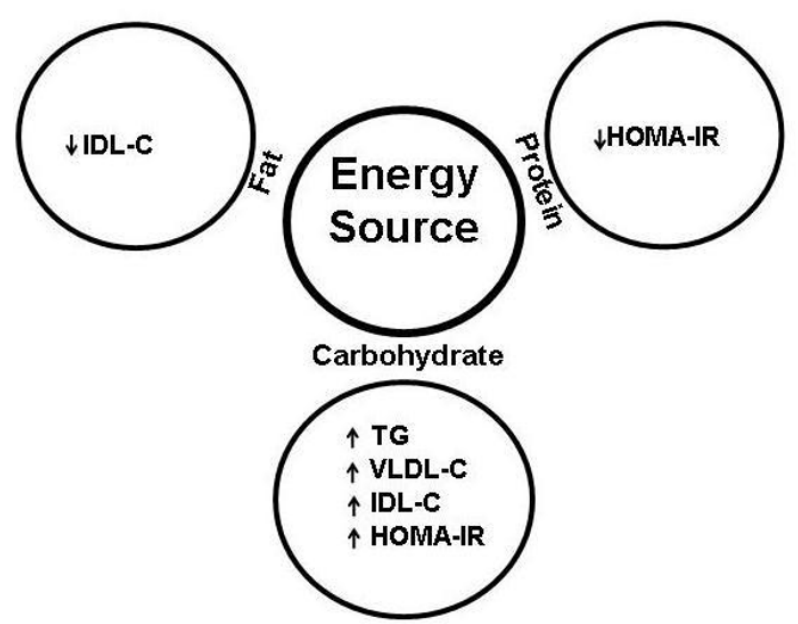

Figure I

Association between source of energy and cardio metabolic risk factors. HOMA-IR, homeostasis model assessment of insulin resistance; IDL-C, IDL cholesterol; $V$ LDL-C, VLDL cholesterol; TG, triglycerides; ISI-FFA, fatty acid insulin sensitivity.

score; HDL-C: High density lipoprotein cholesterol; HOMA-IR: Homeostasis model assessment of insulin resistance; IDL-C: Intermediate density lipoprotein cholesterol; ISI-FFA: Fatty acid insulin sensitivity; LDL-C: Low density lipoprotein cholesterol; NEFA: Non-esterified fatty acids; sBPz: Systolic blood pressure z-score; TC: Total cholesterol; TG: Triglyceride; VLDL-C: Very low density lipoprotein cholesterol; WC: Waist circumference.

\section{Conflict of interests}

The authors declare that they have no competing interests.

\section{Authors' contributions}

Contributor's list: SS contributed in statistical analysis, prepared the manuscript and submission. LSR participated in the development of the protocol, analytical framework for the study and patient screening. MLH provided statistical expertise. RHL provided expertise as a pediatric endocrinologist and child health specialist. SEF was the principal investigator of the study. She supervised the design and execution of the study and manuscript.

\section{Acknowledgements}

The authors gratefully acknowledge the collaboration and excellent assistance provided by the YMCA of the East Bay in Oakland, CA. Essential funding was provided by USDA CSREES grants 2004-352 I4- I4254 and 200535215-15046, the Agriculture Experiment Station and the YMCA. The authors are indebted to the participating children and their families, to the large number of UC Berkeley student assistants, and to Dr. Aarthi Raman, Barbara Green, Rita Mitchell and Mark D. Fitch. Valued consultants on this project include all members of the Advisory Board of the Taking Action Together Project.

\section{References}

I. Ogden CL, Carroll MD, Curtin LR, McDowell MA, Tabak CJ, Flegal KM: Prevalence of overweight and obesity in the United States, 1999-2004. JAMA 2006, 295:I549-I555.

2. Lauer RM, Lee J, Clarke WR: Factors affecting the relationship between childhood and adult cholesterol levels: the Muscatine Study. Pediatrics 1988, 82:309-318.

3. Lauer RM, Clarke WR: Childhood risk factors for high adult blood pressure: the Muscatine Study. Pediatrics 1989, 84:633-64l.

4. Berenson GS, Srinivasan SR, Bao W, Newman WP, Tracy RE, Wattigney WA: Association between multiple cardiovascular risk factors and atherosclerosis in children and young adults. The Bogulasa Heart Study. N Engl J Med 1998, 338: I650-1656.

5. Daniels SR, Greer FR, The Committee on Nutrition: Lipid screening and cardiovascular health in childhood. Clinical report. Pediatrics 2008, 122: 198-208.

6. Egede LE, Dagogo-Jack S: Epidemiology of type 2 diabetes: focus on ethnic minorities. Med Clin North Am 2005, 89:949-975.

7. Dabelea D, Pettitt DJ, Jones KL, Arslanian SA: Type 2 diabetes mellitus in minority children and adolescents. An emerging problem. Endocrinol Metab Clin North Am 1999, 28:709-729.

8. Berenson GS, Wattigney WA, Bao W, Srinivasan SR, Radhakrishnamurthy $B$ : Rationale to study the early natural history of heart disease: the Bogalusa Heart Study. Am J Med Sci 1995, 3 1 0:S22-8.

9. Berenson GS, Srinivasan SR, Nicklas TA: Atherosclerosis: a nutritional disease of childhood. Am J Cardiol 1998, 82:22T-29T.

10. Mensink RP, Zock PL, Kester AD, Katan MB: Effects of dietary fatty acids and carbohydrates on the ratio of serum total to HDL cholesterol and on serum lipids and apolipoproteins: a meta-analysis of 60 controlled trials. Am J Clin Nutr 2003, 77: I 146-I I55.

II. Rolland-Cachera MF, Deheeger M, Akrout M, Bellisle F: Influence of macronutrients on adiposity development: a follow up study of nutrition and growth from 10 months to 8 years of age. Int J Obes Relat Metab Disord 1995, 19:573-578.

12. Skinner JD, Bounds W, Carruth BR, Morris M, Ziegler P: Predictors of children's body mass index: a longitudinal study of diet and growth in children aged 2-8 y. Int J Obes Relat Metab Disord 2004, 28:476-482.

13. Hudgins LC, Baday A, Hellerstein MK, Parker TS, Levine DM, Seidman CE, Neese RA, Tremaroli JD, Hirsch J: The effect of dietary carbohydrate on genes for fatty acid synthase and inflammatory cytokines in adipose tissues from lean and obese subjects. J of Nutri Biochem 2008, 1 9:237-245.

14. Ku CY, Gower BA, Nagy TR, Goran MI: Relationships between dietary fat, body fat, and serum lipid profile in prepubertal children. Obes Res 1998, 6:400-407.

15. Casazza K, Dulin-Keita A, Gower BA, Fernandez JR: Differential influence of diet and physical activity on components of metabolic syndrome in a multiethnic sample of children. J Am Diet Assoc 2009, 109:236-244.

16. Kronsberg SS, Obarzanek E, Affenito SG, Crawford PB, Sabry ZI, Schmidt M, Striegel-Moore R, Kimm SYS, Barton BA: Macronutrient intake of black and white adolescent girls over 10 years: The NHLBI growth and health study. J of the Am Diet Assoc 2003, I 03:852-860.

17. Himes JH, Dietz WH: Guidelines for overweight in adolescent preventive services: Recommendations from an expert committee. Am J Clin Nutr 1994, 59:307-316.

18. Barlow SE, Dietz WH: Obesity evaluation and treatment: Expert committee recommendations. Pediatrics 1998, I 02(3):e29.

19. Bellizzi M, Dietz W: Workshop on childhood obesity: summary of the discussion. Am J Clin Nutr 1999, 70:173S-175S.

20. Raman A, Fitch MD, Hudes ML, Lustig RH, Murray CB, Ikeda JP, Fleming SE: Baseline correlates of insulin resistance in inner city high-BMI African -American children. Obesity 2008, I 6(9):2039-2045.

21. Horlick M, Arpadi SM, Bethel J, Wang J, Moye J Jr, Cuff P, Pierson RN Jr, Kotler D: Bioelectrical impedance analysis models for prediction of total body water and fat-free mass in healthy and HIV-infected children and adolescents. Am J Clin Nutr 2002, 76:991-999. 
22. The fourth report on the diagnosis, evaluation, and treatment of high blood pressure in children and adolescents. Pediatrics 2004, I I 4(2 Suppl 4th Report):555-576.

23. Kullkarni KR, Garber DW, Jones MK, Segrest JP: Identification and cholesterol quantification of low density lipoprotein subclasses in young adults by VAP-II methodology. J of Lipid Res 1995, 36:229|-2302.

24. Gunczler P, Lanes R: Relationship between different fastingbased insulin sensitivity indices in obese children and adolescents. J Pediatr Endocrinol Metab 2006, 19:259-265.

25. Reinehr T, Kiess W, Andler W: Insulin sensitivity indices of glucose and free fatty acid metabolism in obese children and adolescents in relation to serum lipids. Metabolism 2005, 54(3):397-402.

26. Angold A, Costello EJ, Erkanli A, Worthman CM: Pubertal changes in hormone levels and depression in girls. Psychol Med 1999, 29: $1043-1053$

27. Brito VN, Batista MC, Borges MF, Latronico AC, Kohek MBF, Thirone $A C P$, Jorge BH, Arnhold IJP, Mendonca BB: Diagnostic value of fluorometric assays in the evaluation of precocious puberty. J Clin Endocrinol Metab 1999, 84:3539-3544.

28. Horlick MB, Rosenbaum M, Nicolson M, Levine LS, Fedun B, Wang J, Pierson RN Jr, Leibel RL: Effect of puberty on the relationship between circulating leptin and body composition. J Clin Endocrinol Metab 2000, 85:2509-25I8.

29. Sehested A, Andersson AM, Muller J, Skakkebaek NE: Serum inhibin $A$ and inhibin $B$ in central precocious puberty before and during treatment with GnRH agonists. Horm Res 2000, 54:84-9l.

30. Ferlin A, Garolla A, Rigon F, Caldogno LR, Lenzi A, Foresta C: Changes in serum insulin-like factor 3 during normal male puberty. J Clin Endocrinol Metab 2006, 9 1:3426-343I.

31. Raman A, Lustig R, Fitch MD, Fleming S: Accuracy of self assessed tanner staging against hormonal assessment of sexual maturation in overweight African -American children. J Pediatr Endocrinol Metab 2009, 22:609-622.

32. Crawford PB, Obarzanek E, Morrison J, Sabry Zl: Comparative advantage of 3-day food records over 24-hour recall and 5day food frequency validated by observation of 9- and 10year-old girls. J Am Diet Assoc 1994, 94:626-630.

33. Services USDAARS: What's in the Foods You Eat search tool, version 2.0. USDA: Agricultural Research Services. [http:// www.ars.usda.gov]. Accessed May 21, 2007

34. Third Report of the National Cholesterol Education Program. Expert Panel on Detection, Evaluation, and Treatment of High Blood Cholesterol in Adults (Adult Treatment Panel III). In Executive Summary Bethesda, Md.: National Institutes of Health, National Heart Lung and Blood Institute (NIH publication no. 0l-3670); 2001.

35. Urrutia-Rojas X, Menchaca J: Prevalence of risk for type 2 diabetes in school children. I Sch Health 2006, 76: I89-194.

36. Falkner B, Michel S: Obesity and other risk factors in children. Ethn Dis 1999, 9:284-289.

37. Falkner B, Sherif K, Sumner A, Kushner H: Hyperinsulinism and sex hormones in young adult African Americans. Metabolism 1999, 48:107-112.

38. Savva SC, Tornaritis M, Savva ME, Kourides Y, Panagi A, Silikiotou N, Georgiou C, Kafatos A: Waist circumference and waist-toheight ratio are better predictors of cardiovascular disease risk factors in children than body mass index. Int J Obes Relat Metab Disord 2000, 24: |453-|458.

39. Janssen I, Katzmarzyk PT, Srinivasan SR, Chen W, Malina RM, Bouchard C, Berenson GS: Combined influence of body mass index and waist circumference on coronary artery disease risk factors among children and adolescents. Pediatrics 2005, I I 5: |623-1630.

40. Ford ES, Liu S: Glycemic index and serum high-density lipoprotein cholesterol concentration among US adults. Arch Intern Med 2001, 1 61 :572-576.

4I. Krauss RM, Blanche PJ, Rawlings RS, Fernstrom HS, Williams PT: Separate effects of reduced carbohydrate intake and weight loss on atherogenic dyslipidemia. Am J Clin Nutr 2006, 83: $1025-103 \mid$.

42. Reaven GM: Compensatory hyperinsulinemia and the development of an atherogenic lipoprotein profile: the price paid to maintain glucose homeostasis in insulin-resistant individuals. Endocrinol Metab Clin North Am 2005, 34:49-62.

43. Pilz S, Scharnagl H, Tiran B, Seelhorst U, Wellnitz B, Boehm BO, Schaefer JR, März W: Free fatty acids are independently associated with all-cause and cardiovascular mortality in subjects with coronary artery disease. J Clin Endocrinol Metab 2006, 9 I:2542-2547.

44. McCarthy WJ, Yancey AK, Siegel JM, Wong WK, Ward A, Leslie J, Gonzalez E: Correlation of obesity with elevated blood pressure among racial/ethnic minority children in two Los Angeles middle schools. Prev Chronic Dis 2008, 5(2):A46.
Publish with Bio Med Central and every scientist can read your work free of charge

"BioMed Central will be the most significant development for disseminating the results of biomedical research in our lifetime. "

Sir Paul Nurse, Cancer Research UK

Your research papers will be:

- available free of charge to the entire biomedical community

- peer reviewed and published immediately upon acceptance

- cited in PubMed and archived on PubMed Central

- yours - you keep the copyright 